\title{
$\infty \sqrt{1}$ Stroke and \\ AHORA: a Spanish language tool to identify acute stroke symptoms
}

\author{
Paul Banerjee, ${ }^{1,2,3}$ Helene Koumans, ${ }^{4}$ Madison Danielle Weech, ${ }^{5}$ Maricela Wilson, ${ }^{6}$ \\ Mark Rivera-Morales, ${ }^{2,3}$ Latha Ganti (D) ${ }^{1,2,3,7}$
}

To cite: Banerjee $\mathrm{P}$, Koumans $\mathrm{H}$, Weech MD, et al. AHORA: a Spanish language tool to identify acute stroke symptoms. Stroke \& Vascular Neurology 2021;0. doi:10.1136/svn-2021-001280

Received 14 August 2021 Accepted 9 September 2021
Check for updates

(C) Author(s) (or their employer(s)) 2021. Re-use permitted under CC BY-NC. No commercial re-use. See rights and permissions. Published by BMJ.

${ }^{1}$ Fire Rescue, Polk County Florida, Bartow, Florida, USA ${ }^{2}$ Department of Emergency Medicine, University of Central Florida College of Medicine, Orlando, Florida, USA

${ }^{3}$ Osceola Regional Medical Center, Kissimmee, Florida, USA

${ }^{4}$ Department of Biology and Medicine, Brown University, Providence, Rhode Island, USA ${ }^{5}$ Department of Biology, University of Florida, Gainesville, Florida, USA

${ }^{6}$ Stroke Community Outreach, Seton Healthcare Family, Austin, Texas, USA

${ }^{7}$ Department of Neurology, University of Central Florida College of Medicine, Orlando, Florida, USA

Correspondence to Dr Latha Ganti;

latha.ganti@ucf.edu

\section{ABSTRACT}

Objective To develop a Spanish language tool for acute stroke identification.

Methods A Spanish language translation of the BalanceEyes-Face-Arm-Speech-Time tool was developed within our emergency medical services agency.

Results The authors present a new prehospital stroke tool, Andar, Hablar, Ojos, Rostro and Ambos Brazos o Piernas (AHORA) (which means now in Spanish) to help combat the language barrier and reinforce the necessity to call 9-1-1 as soon as any stroke symptoms are noted.

Conclusion AHORA is a Spanish language tool that aims to help Spanish-speaking individuals to identify an acute stroke and obtain prompt help.

\section{BACKGROUND}

Every $40 \mathrm{~s}$, someone suffers a stroke in the USA alone. ${ }^{1}$ According to WHO, 15 million people suffer stroke worldwide each year, and stroke is the number one cause of disability worldwide. ${ }^{2}$ For patients who had a stroke, the length of time between symptom onset and the receipt of treatment can determine their prospect of recovery or permanent disability. For example, patients who are able to receive thrombolytic therapy for their acute ischaemic stroke are $30 \%$ more likely to be alive and with better functional ability at 90 days compared with their counterparts. ${ }^{3}$ Furthermore, for every 15 min delay from time of onset of symptoms to thrombolytic therapy, there is $3 \%$ greater odds of not walking independently at discharge, and being discharged to an institution rather than home, and $4 \%$ higher odds of in-hospital death or haemorrhagic transformation of the infarct. ${ }^{4}$

According to the 2019 US Census Bureau estimate, there are more than 60 million Hispanic individuals residing in the USA. ${ }^{5}$ The Hispanic population is very diverse, differing in national origin, race, immigration status, language fluency and other socioeconomic factors. However, despite this diversity and the increasing numbers, strokes are the leading cause of disability and the thirdleading cause of death in the Hispanic population (stroke is the fifth-leading cause of death overall). Mexican Americans compose the largest share of the Hispanic population as well as $18.4 \%$ of the US total population, ${ }^{5}$ and compared with non-Hispanic whites, Mexican Americans have a higher incidence of both ischaemic and intracerebral haemorrhage stroke as well as a higher stroke mortality, particularly at older ages. ${ }^{6}$ In 2018, 2.8\% of Hispanic men and $2.3 \%$ of Hispanic women suffered from stroke, compared $3.1 \%$ and $2.3 \%$ of non-Hispanic white men and women in an age-adjusted model. ${ }^{78}$ In the same year, Hispanic men and women exhibited stroke death rates of 34.2 and 29.9 per 100000 , respectively, while non-Hispanic white men and women exhibited stroke death rates of 35.7 and 35.6 per 100000 , respectively. ${ }^{78}$ The American Heart Association and American Stroke Association project that stroke prevalence will increase by $20.50 \%$ between 2012 and 2030-the greatest rise among white, Hispanic men. ${ }^{9}$

Considering the significance of time, the Stroke Heroes Act FAST kit was produced in 2006 by the Stroke Prevention and Control Programme at the Massachusetts Department of Public Health. ${ }^{10}$ Prior to 1998 when the Brain Attack Coalition reached a consensus, standardised definitions for stroke signs and symptoms were not available, and in 2003 a mere $18 \%$ of Massachusetts adults were aware of all stroke symptoms. ${ }^{11}$ A 2008 study in a well-educated population revealed only $21 \%$ had ever heard of thrombolytic therapy for stroke ${ }^{12}$ highlighting the need for public awareness. Since early recognition of stroke symptoms allows for early treatment and thus better clinical outcomes, the kit intended to increase stroke symptom recognition in order to improve stroke survival and treatment outcomes. ${ }^{11}$ Prior public education campaigns demonstrated their success in promoting stroke symptom recognition, and the FAST kit aimed to develop an evidencebased, comprehensive, and lasting campaign to this effect. ${ }^{1314}$ During the FAST retention pilot, significant increases were observed in the share of participants able to recognise stroke symptoms and the immediate need to 
call 9-1-1, and nearly all participants retained the information 3 months later. ${ }^{11}$ The pilot for message retention, however, was conducted in English with a population predominantly composed of non-Hispanic white women with a mean age of 53.7 years. ${ }^{11}$ Although the FAST campaign has been successful in many regards, sociodemographic disparities in awareness of stroke symptoms persist, with non-Hispanic black and Hispanic young adults much more likely to be unaware of stroke symptoms than their non-Hispanic white counterparts. ${ }^{15}$

According to a 2021 Hispanic Community Health Study/Study of Latinos, Hispanic individuals exhibit high prevalence of 'modifiable vascular risk factors (VRFs), and nearly ' $90 \%$ of the stroke risk is attributable to modifiable VRFs' ${ }^{16}$ Modifiable risk factors include language barrier, lack of trust in the medical system, access to healthcare facilities and culturally tailored care. ${ }^{16}$ Language preference in particular has profound effects on health status and literacy. ${ }^{17}$ According to Behavioural Risk Factor Surveillance System (BRFSS) data, Spanishspeaking Hispanic individuals in nearly half of US states 'reported far worse health status' and poorer access to healthcare than English-speaking Hispanic individuals. ${ }^{17}$ To this end, Spanish-speaking Hispanic individuals are much more likely to be unaware of stroke symptoms than English-speaking Hispanic and non-Hispanic populations. ${ }^{17}$ A cross-sectional analysis of the BRFSS data compared 698 English-speaking Hispanics, 527 Spanishspeaking Hispanics, and 24201 non-Hispanics, and found that Spanish-speaking Hispanics were significantly more likely to not know all the stroke symptoms, underscoring the fact that 'low English language proficiency identifies a subpopulation of Hispanics with substantially less awareness of symptoms requiring immediate medical attention'-fewer than 20\% of the Spanish-speaking Hispanic population were able to identify all stroke symptoms. ${ }^{18}$ Although language proficiency and preference do not account for all VRFs, it is evident that they play a consequential role. ${ }^{19}$ In order to address this disparity, it is essential that there be a higher share of Spanish-speaking and culturally tailored healthcare professionals and caregivers, improved translation and interpretation services, and more health material accessible to the Spanishspeaking Hispanic population.

\section{PRACTICE INNOVATION}

The Polk County Fire and Rescue of Polk County, Florida developed the acronym AHORA, and incorporated this tool into their protocol as of 1 January $2021 .{ }^{20}$ AHORA (figure 1) is an acronym that stands for Andar, Hablar, Ojos, Rostro and Ambos Brazos o Piernas-translating to walking, speech, eyes, face and both arms or legs. ${ }^{21} 22$ Just as is instructed by Balance-Eyes-Face-Arm-Speech-Time (BEFAST), should an individual answer in the affirmative to any of the accompanying questions (eg, Does the person have trouble balancing? Does the person have trouble speaking or understanding? Has half of the

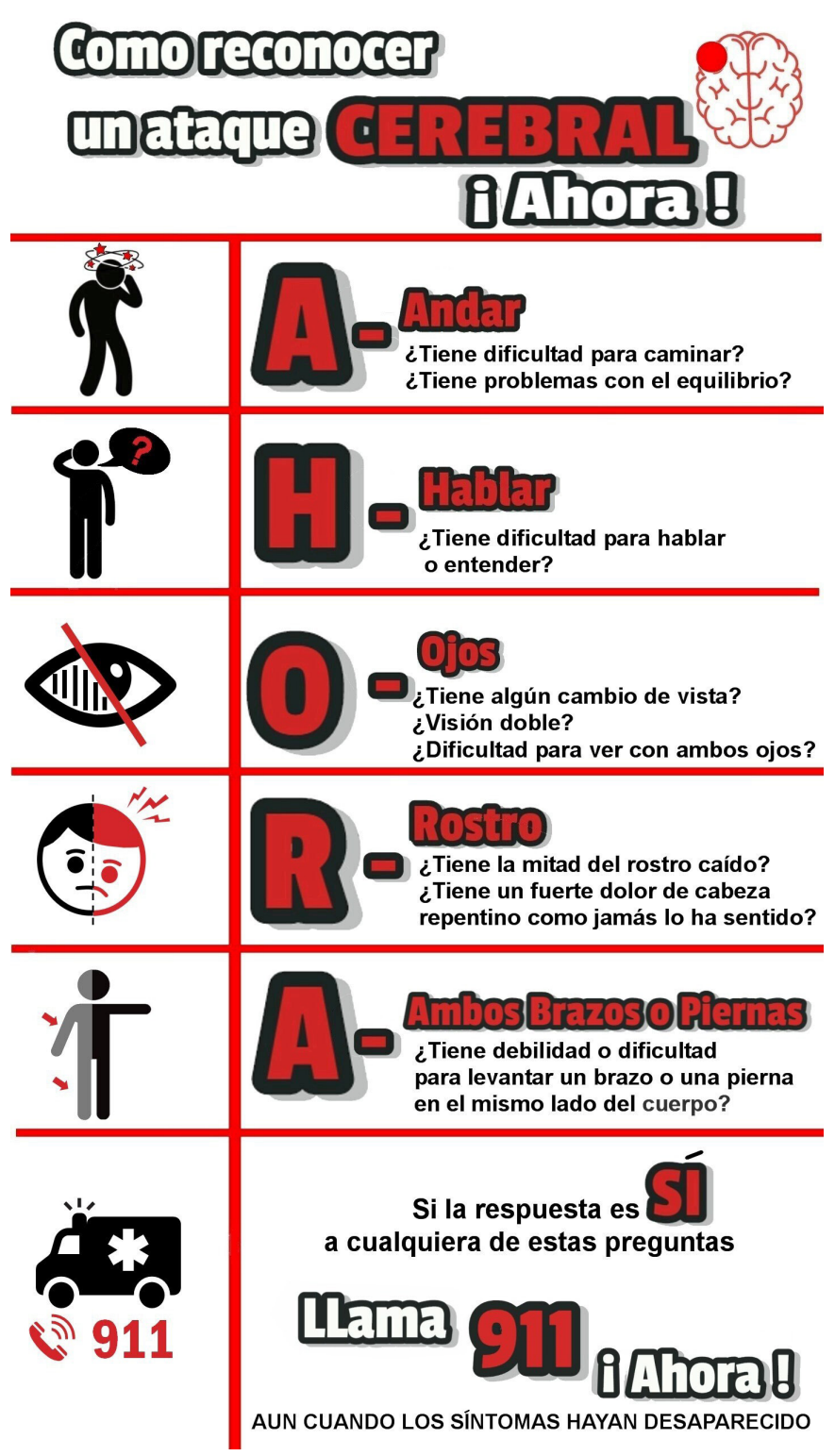

Figure 1 How to recognise a stroke AHORA.

person's face drooped?), 9-1-1 should be called immediately even if symptoms have resolved. The instruction to call 9-1-1 AHORA echoes that of BEFAST because, as per the American Heart and American Stroke Associations, 'time lost is brain lost' when one suffers a stroke. ${ }^{2324}$ Rapid assessment by emergency medical services and transport to a stroke centre arecritical, and symptom recognition and perception of an emergency situation lead to faster arrival to the emergency department. ${ }^{25-27}$ AHORA has the added advantage of meaning 'now', further underscoring the immediacy of the situation.

\section{CONCLUSION}

Among the Spanish-speaking Hispanic population, significant delays exist in presentation for treatment and care, especially during stroke and acute myocardial infarction. Effective, accessible community and public health campaigns to educate this demographic on stroke 
symptoms, using a tool such as AHORA, are critical in minimising delay in seeking medical care.

Twitter Latha Ganti @LathaGanti

Contributors PB, MW conceived the study. HK, LG, MR-M and MDW drafted the manuscript, and all authors approved the final version.

Funding This research was supported (in whole or in part) by HCA Healthcare and/ or an HCA Healthcare affiliated entity.

Disclaimer The views expressed in this publication represent those of the author(s) and do not necessarily represent the official views of HCA Healthcare or any of its affiliated entities.

Competing interests None declared.

Patient consent for publication Not applicable.

Provenance and peer review Not commissioned; externally peer reviewed.

Open access This is an open access article distributed in accordance with the Creative Commons Attribution Non Commercial (CC BY-NC 4.0) license, which permits others to distribute, remix, adapt, build upon this work non-commercially, and license their derivative works on different terms, provided the original work is properly cited, appropriate credit is given, any changes made indicated, and the use is non-commercial. See: http://creativecommons.org/licenses/by-nc/4.0/.

ORCID iD

Latha Ganti http://orcid.org/0000-0001-7717-3864

\section{REFERENCES}

1 Centers for Disease Control and Prevention. Stroke facts, 2020. Available: www.cdc.gov/stroke/facts.htm [Accessed 17 Jul 2021].

2 World Health Organization. Stroke, cerebrovascular accident. Available: http://www.emro.who.int/health-topics/strokecerebrovascular-accident/index.html [Accessed 17 Jul 2021].

3 National Institute of Neurological Disorders and Stroke rt-PA Stroke Study Group. Tissue plasminogen activator for acute ischemic stroke. N Engl J Med 1995;333:1581-8.

4 Saver JL, Fonarow GC, Smith EE, et al. Time to treatment with intravenous tissue plasminogen activator and outcome from acute ischemic stroke. JAMA 2013;309:2480-8.

5 Office of Minority Health. Hispanic/Latino-The office of minority health. U.S. department of health and human services, 2021. Available: https://minorityhealth.hhs.gov/omh/browse.aspx?lvl=3\& Ivlid=64 [Accessed 17 Jul 2021].

6 Morgenstern LB, Smith MA, Lisabeth LD, et al. Excess stroke in Mexican Americans compared with non-Hispanic whites: the brain attack surveillance in corpus Christi project. Am J Epidemiol 2004;160:376-83.

7 Villarroel MA, Blackwell DL, Jen A. Tables of summary health statistics for U.S. adults: 2018 National health interview survey. National Center for Health Statistics, 2019. https://ftp.cdc.gov/pub/ Health Statistics/NCHS/NHIS/SHS/2018 SHS Table A-1.pdf

8 Stroke and Hispanic Americans. U.S. department of health and human services office of minority health, 2021. Available: https:// minorityhealth.hhs.gov/omh/browse.aspx? $|v|=4 \& \mid v l i d=73$ [Accessed 17 Jul 2021].

9 Ovbiagele B, Goldstein LB, Higashida RT, et al. Forecasting the future of stroke in the United States: a policy statement from the
American heart association and American stroke association. Stroke 2013;44:2361-75.

10 Massachusetts Department of Public Health Stroke Prevention and Control Program. Stroke signs and symptoms: act F.A.S.T, 2021. Available: https://www.mass.gov/service-details/stroke-signs-andsymptoms-act-fast [Accessed $17 \mathrm{Jul} 2021]$.

11 Wall HK, Beagan BM, O'Neill J, et al. Addressing stroke signs and symptoms through public education: the stroke heroes act fast campaign. Prev Chronic Dis 2008:5:A49.

12 Stead LG, Vaidyanathan L, Bellolio MF, et al. Knowledge of signs, treatment and need for urgent management in patients presenting with an acute ischaemic stroke or transient ischaemic attack: a prospective study. Emerg Med J 2008;25:735-9.

13 Becker K, Fruin M, Gooding T, et al. Community-Based education improves stroke knowledge. Cerebrovasc Dis 2001;11:34-43.

14 Alberts MJ, Perry A, Dawson DV, et al. Effects of public and professional education on reducing the delay in presentation and referral of stroke patients. Stroke 1992;23:352-6.

15 Mszar R, Mahajan S, Valero-Elizondo J, et al. Association between sociodemographic determinants and disparities in stroke symptom awareness among US young adults. Stroke 2020;51:3552-61.

16 Bai F, Chen J, Pandey D, et al. Stroke risk factor status and use of stroke prevention medications among Hispanic/Latino adults in HCHS/SOL. Stroke 2021;52:1339-46.

17 Rodriguez CJ, Allison M, Daviglus ML, et al. Status of cardiovascular disease and stroke in Hispanics/Latinos in the United States. Circulation 2014;130:593-625.

18 DuBard CA, Garrett J, Gizlice Z. Effect of language on heart attack and stroke awareness among U.S. Hispanics. Am J Prev Med 2006;30:189-96.

19 Timmins CL. The impact of language barriers on the health care of Latinos in the United States: a review of the literature and guidelines for practice. J Midwifery Womens Health 2002;47:80-96.

20 Wilson M, Crowe R, Banerjee P. Recognizing a stroke, 2021. Available: https://www.dshs.state.tx.us/heart/pdf/AHORARecognizing-a-Stroke.pdf

21 Bassett J. Five questions with: Dr. Remle Crowe on stroke education for Spanish-speaking communities. EMSWorld, 2021. Available: https://www.hmpgloballearningnetwork.com/site/emsworld/article/ 1225717/five-questions-dr-remle-crowe-stroke-education-spanishspeaking-communities [Accessed $17 \mathrm{Jul}$ 2021].

22 Wilson M, Crowe R, Banerjee P. The time for Spanish-language stroke community outreach efforts is AHORA. EMS1, 2021. Available: https://www.ems1.com/stroke-care/articles/the-time-forspanish-language-stroke-community-outreach-efforts-is-ahoraxxJdr9dKCIRMXJn5/ [Accessed 17 Jul 2021].

23 American Heart Association \& American Stroke Association. With a stroke, time lost is brain lost. American heart association, 2012. Available: http://www.strokeassociation.org/idc/groups/heartpublic/@wcm/@global/documents/downloadable/ucm_312284.pdf [Accessed 17 Jul 2021].

24 Saver JL. Time is brain--quantified. Stroke 2006;37:263-6.

25 Hemmen T. Patient delay in acute stroke response. Eur J Neurol 2008:15:315-6.

26 Henderson SO, Magana RN, Korn CS, et al. Delayed presentation for care during acute myocardial infarction in a Hispanic population of Los Angeles County. Ethn Dis 2002;12:38-44.

27 DuBard CA, Gizlice Z. Language spoken and differences in health status, access to care, and receipt of preventive services among US Hispanics. Am J Public Health 2008;98:2021-8. 